than six weeks, and was only cured at last by metastasis to the testicles. I adopted no preparatory treatment in his case, for reasons already given, but applied the nitrate of silver at once, with perfect success.

The fourth, and last, presents us with the disease in the primary stage. The inflammatory action is as yet confined to the orifice and a little way down the urethra, the parts coming directly in contact with the virus at the time of infection. The object, then, is, to cut the disease short, by preventing further extension of the inflammation by means of the nitrate of silver. For this purpose it is applied, not only to the part really affected, but to some distance beyond it. The treatment proves successful, for although the symptoms are at first increased, they soon after begin to diminish, and at the expiration of two or three days they have entirely disappeared, and the original disease no longer exists.

Surely, then, no treatment can be more simple or rational than this, or more consonant with the recognised therapeutic action of the remedy employed. For is it not well known that nitrate of silver possesses, in a remarkable degree, the power of arresting many kinds of inflammation in various textures of the body, when applied to them either in the liquid or solid form? If, for instance, applied around the margin of erysipelatous inflammation of the skin, will it not, in nine cases out of ten, prevent its farther extension? Or if applied to the mucous membrane in some particular forms of sore throat, will it not then also form, as it were, a boundary over which the inflammatory action rarely passes? Many more instances of the same sort might be adduced, but it is unnecessary to multiply them.

In the disease, however, under consideration, may it not also act in another capacity? May it not, from its corrosive quality, act upon the poison, the real infectious matter itself, and by destroying it thus convert a disease which before had depended upon a "specific virus," into one of simple inflammatory action only?

London, Nov. 5, 1844.

\section{RUMINATION IN THE HUMAN SUBJECT.}

By Robert Read, Veterinary Surgeon, Crediton.

F. L- aged twenty-four, an idiot and an inmate of the Crediton Union Workhouse, possesses this singular propensity, so foreign to man. He rejects, if offered to him, every kind of compact animal food, but eagerly devours, with imperfect mastication, farinaceous and other vegetable substances, more especially boiled potatoes, of which he is very fond; in fact, he subsist almost wholly on a vegetable diet, with the exception, occasionally, of a little broth. Animal food, when offered to him, is thrown away with displeasure. After he has made a repast, he wil sometimes, in from ten to twenty minutes, begin to regurgitate and to remasticate the food over again; at other times, an hour or even more will pass away before any attempt to ruminate is made. The act with him is perfectly voluntary, as he can command it or suspend the same at his will or pleasure. The act of regurgitating his food does not produce any uneasy or disquiet feeling, neither does it create the least semblance to vomition, in which the efforts are painful and convulsive. His position is generally, when in the act of chewing his food over again, fixed, with his back against a wall; he then raises his shoulders, contracts the abdominal muscles, so as to press against the stomach, and makes an expiration. Thus the fuod is again, with every appearance of ease, returned to the mouth for a second mastication. This act of rumination I have no doubt he contirues until he has brought all the solid parts of his food into a semi-fluid state. He seems to enjoy the process of rumination more than his meal; as, in the latter, it is hastily devoured, whilst in the former he seems to be quiet, calm, and pleased. Excitement or alarm, or any mistrust or attention to him, will make him suspend the act, but as soon as such causes are absent, he again returns to rumination, chewing the food over again. Rumination is peculiar only to animals which are classed under the order ruminantia, herbivora, possessing a plurality of stomachs. In the ox, the food does not return again to the same receptacle from which it is regurgitated. Rumination therefore in man must differ in this respect, as it is highly improbable there is more than one stomach in man-ruminants; bot the comparative repose and quiet in each is not dissimilar during the act. The reason, speaking physiologically, why this man-ruminant refuses animal food, may be from the change effected in the stomach during digestion, whereby something nauseous is eliminated, rendering the pellet returned to his mouth disagreeable to the taste, whilst a diet purely vegetable during the digestive process may generate a saccharine agent, and thus render its rumination more pleasing to him. Some cases are recorded in which the act of ramination in man is one of a painful effort, attended with spasmodic and other convulsive signs, effusion of tears, and the eres bursting from their orbit. It is not the case with the one I have detailed. Many of the readers of THE LANCET can now theorize on the subject of rumination in man; I have supplied the outlines of the case as near as I can. Comparative anatomists agree that all ruminant animals are quadrupeds, "viviparous," and have four stomachs; but in the case of this poor idiot there is an exception to the general rule, which can only be determined by an examination after death. Diversity exists as to the relative quality of the food for rumination in man and the ox; the latter scarcely, if ever, returns farinaceous food or boiled bulbous roots, as by the first mastication and the action of the paunch they are reduced sufficiently to a pultaceous mass; the comminuting process is only required the second time when staminaceous food forms their diet, whilst in man who ruminates, animal food is rejected, and bulbous food is chosen for remastication, as is clearly exemplified in this case. The contractile power of his stomach seems to be very great, as when teased or irritated he will eject the fluid contents of his stomach to a considerable distance through his mouth. In so doing he must make the osophagus a passive tube, as no resistance seems to be offered by it. In concluding this most interesting case, I can only say it is surprising that it has remained so long unheeded and unrecorded in any medical journal, although seen by so many medical men. I beg pardon of them for publishing it, but must say that the ruminating part of the question is more applicable to my province and practice.

January, 1845 .

\section{ON GRAVEL IN THE TUBULI URINIFERI.}

By Spencer T. Smyth, M. R. C. S. England; L. A. C. London.

A sHort period since I was consulted by the mother of an infant, aged ten months, owing to the following circumstance:The latter, a strong and healthy child, was at times seized with convulsions to an alarming degree, attacks of which would manifest themselves frequently during the space of twenty-four hours. Upon interrogating the mother, it was ascertained that the bowels were daily relaxed, but when evacuating his bladder, the child was observed to suffer greatly, and then the symptoms of convulsions, to a greater or less extent, displayed themselves; the urine was very scanty in quantity, highly acid, and depositing a lateritious sediment; occasionally, none was passed for a day and a night. Under this condition, mild mercurial alteratives, with alkalies, in combination with hyoscyamus, were administered, with the daily use of warm baths, strict attention being, at the same time, pdid to the diet of the little individual. Two or three days after the above treatment was steadily pursued, the urine was passed much more freely, and to a larger amount. Upon examining the napkin, several minute particles of lithic acid were observable; these continued to pass for several days, after which the convulsive paroxysms abated. This case, I consider, was one of gravel in the tubuli uriniferi of the kidneys, which phenomenon has been so frequently observed in new-born infants by Professor Engel, of Vienna, that he considers it a normal condition. Dr. Schlossherger has remarked, that on making a longitudinal section of the kidney of the infant thus affected, you will find, on both cut surfaces, the urinary tubuli passing from the papillæ up to the extremity of the cortical substance, beautifully injected with a yellow powder; by pressing on the canals, the powder passes, with a quantity of dark fluid, into the renal pelvis, which, also, is itself somewhat filled with a similar powder. Chemical analysis shews that it always contains lithic acid, and urinary colouring matter, a beautiful red colour, and effervescence being produced when it is heated with nitric acid. The lithic diathesis of infants is mostly connected with some derangement existing in the alimentary canal, (most probably owing to the administration of improper food,) manifested in many diseases at this tender age; for, even in adults, disturbances of the intestinal canal, liver, \&c., favour the production of an excess of lithic acid. Infants are greatly exposed to variations of temperature, which (temperature) is apt to become suddenly depressed. In old persons, Magendie considers this low state of temperature to be the chief cause of the formation of urinary calculi, inasmuch as the urine is then unable to hold the same quantity of lithic acid in solation; this circumstance must be greatly increased in infants, whose diseases so frequently manifest a marked depression of animal heat. The deposition of urinary gravel in the tubuli uriniferi of infants is explained by Dr. Schlossberger in this way, that the sudden cooling of the temperature operates, perhaps, as an astringent on the papillæ of the kidney, by which means, the lithic acid, which abounds in their urine, is precipitated as a lateritious sediment; perhaps spasms or obstruction of the papilla sometimes take place through inflammatory action. No cause has as yet been assigned, in the size of the uriniferous tubes themselves, for they 
are comparatively larger in the newly-born infant than in the adult.

The use of warm baths in such cases must be highly beneficial, as they tend to promote the natural excretion of the cutaneous surface. The urine not only contains lithic acid, in combination with ammonia, thus rendering the acid soluble in it, but also lactic acid, and various salts. This latter acid is the predominant one in the perspiration, and therefore if the functions of the skin be in the least degree checked, the kidneys will be called into action, to assist in unloading the system of this superabundant lactic acid, that ought to be removed, in a great measure, by means of the perspiratory fluid; it is when the urine contains a superabundance of lactic acid, that the lithic acid sand becomes, for the most part, precipitated; therefore, for this reason, the state of the skin should al ways be well observed. It is well known, that upon the eastern coast of England, the urine of persons there residing contains an excess of lithic acid, owing to which circumstance the formation of urinary calculi is very frequent. This is accounted for by the sudden check to the perspiration, occasioned by the length of time at which the easterly winds prevail in some parts of the year.

Upon this subject many remarks might be adduced; but not wishing to intrude longer upon the valuable columns of Trim LaNCET, I must beg for the present to postpone doing so.

Gorleston, Suffolk, Jan. 26, 1845.

\section{ON AMPUTATION OF THE PENIS.}

By Robent Barnts, M.B. Londin.

Onserving, in last week's Lancex, a very excellent lecture by Mr. Hancock, on cancer of the penis, in which he describes the method of amputating that organ, together with the proceedings necessary to secure the orifice of the urethra from becoming obliterated by contraction, I am induced to think that it will not be superfluous to call attention to the method practised by $M$. Ricord, with the view of obviating this inconvenience. I am not aware that this method has been described in the British medical journals, certainly $\mathrm{Mr}$. Hancock has made no reference to it. That some proceeding is necessary to be adopted in order to preserve the urethra from closure, has been universally recognised. In a case of amputation of the penis which I witnessed some years ago in the country, in which no attention was paid to this point, the orifice of the urethra could with difficulty be preserved from obliteration by the constant use of a bougie.

The principle of Mr. Hancock's operation, and of Mr. Earle's, is to counteract contraction. M. Ricord's principle is to avail himself of this process of contraction, and turn it to account in preserving the orifice of the urethra patent. The proceeding is this-having performed the amputation, with the precaution of preserving sufficientskin, and no more, to sheathe the corpora cavernosa, and secured the vessels, the surgeon seizes with the forceps the mucous membrane of the urethra, and with a pair of scissors makes four slight incisions, so as to form four equal flaps then using a fine needle, carrying a silk ligature, he unites each flap to the skin by a suture. The wound unites by the first intention; adhesions being formed between the skin and mucous membrane, which become continnous, a condition analogous to what is observed at the other natural outlets of the body. The cicatrix then contracting, instead of operating prejudicially, as in the old methods, tends, on the contrary, constantly to open the urethra, whilst a perfect covering is provided for the ends of the corpora cavernosa. In the spring of 1843 , I had the satisfaction of seeing this ingenious operation performed by $\mathbf{M}$. Ricord, at the Hopital du Midi; when I saw the patient, eight days afterwards, the sutures had been removed, union had taken place between the skin and mucous membrane, and the urine has freely passed without the intervention of a catheter. I saw this patient again when he was about to leave the hospital, at which time the cicatrix was complete, the orifice of the urethra patent; there was an excellent stump, and, in short, the operation appeared to be perfectly successful. M. Ricord has performed the operation in other cases, and, he reports, with the same happy results. I have performed the operation many times on the subject, and have found no difficulty in the execution of it.

Another inconvenience mentioned by Mr. Hancock, the difficulty of directing the stream of urine, is one which becomes troublesome in proportion to the shortness of the stump. It may be obviated by the contrivance recommended by Ambrose Paré. The patient must provide himself with a funnel-shaped canula, made of box, ivory, or metal, the base of which, being applied over the stump, and resting on the pubes, the other end will serve to carry the urine clear of the person.

Bulmer House, Notting Hill, February 11 th, 1845 .

\section{BRITISH AND AMERICAN MEDICAL} JOURNALS.

\author{
THE DELETERIOUS INFLUENCE OF THE EXCESSIVE USE OF
}

TOBACCO.

Tobacco is denounced by Dr. Chapman as a fertile source of dyspepsia. The British and Foreign Review remarks-

"On this subject, an American physician may truly speak, $e x$ cathedra. Although we cannot as yet pretend to compete with Americans in the practice of this di:gusting vice, we see too much of it, not to know that, even in the small way here perpetrated, it is almost as injurious to the health of our young men as it is nauseous to the senses of their unsmoking victims. We almost wish they would, like Dr. Chapman's senator, come to 'chewing and snuffing as well as smoking,' that the full abomination of the thing might cure itself.

" : By a member of congress from the West, in the meridian of life, and of a very stout fiame. I was some time since consulted; he told me that fiom having been one of the most healthy and fearless of men, he had become 'sick all over and as timid as a girl.' He could not even present a petition to congress, much less say a word concerning it, though he had long been a practising lawyer, and served much in legislative bodies. By any ordinary noise he was startled or thrown into tremulousness, and afraid to be alone at night. His appetite and digestion were gone, he had painful sensations at the pit of his stomach, and unrelenting constipated bowels. During the narrative of his sufferings his aspect approached the haggard wildness of mental distemperature. On inquiry $I$ found that his consumption of tobacco was almost incredible, by chewing, snuffing, and smoking. Being satisfied that all his misery arose from this poisonous weed, its use was discontinued, and in a few weeks he entirely recovered.

" 'Distressing as was this case, I have seen others, from the same cause, even more deplorable. Two young men were in succession brought to me for advice, whom $I$ found in a state of insanity, very much resembling delirium tremens. Each had chewed and smoked tobacco to excess, though perfectly temperate as regarded drink. The farther account given me was, that early in life, adopting this bad practice, it grew with their growth. Dyspepsia soon occurred, attended by great derangement of the nervous system, and ultimately the mania I have mentioned. But I have also seen the same condition very speedily induced."

THE SELF-PROPELIING POWERS OF THE BLOOD.

By placing under the field of the microscope the most trans parent part of the web of the foot of a very small frog, Dr. Green has observed many capillary vessels so minute as to be capable of admitting only a single file of red globules. 'These globules may often be seen running different directions in paraliel vessels; and, not unfrequently, single globules, and sometimes two or three together, may be observed, separated apparently at a considerable distance from any others, and yet moving on slowly in some instances, and rapidly in others, independent of any vis à tergo power; so that, as the contractile power of the capillaries (except so far as regards the natural elasticity of their coats) is denied by these physiologists, the motion of these single globules must be independent of the heart's action, and dependent on an inherent power of their own. Not only this, but not unfrequently, in watching the current of globules in these minute vessels, he has observed them to be suddenly arrested, and then to recede for some distance along the course of the vessel. This phenomenon is accounted for by Müller, on the supposition that the vessels may have been compressed by slight motions of the frog. This could not have been the case in one instance which he recently noticed, where a capillary vessel was seen to pass directly through the centre of a pigment cell, in a frog's foot. In this vessel, red globules were seen repeatedly to run in different directions in the same vessel, and to pass each other in the centre of the cell. If the motion of the blood in the capillaries is entirely dependent upon the heart's action, how can we account for this power being exerted in different directions in the same ressel?

Other evidences of this inherent power of the blood have been observed. Having removed an elongated uvula, a few days since, the most transparent portion of the truncated part was placed under the field of the microscope. Upwards of half an hour after the part was excised, the blood was seen to move slowly along the capillary vessels; and yet the precaution was taken to keep the piece moistened, so that the vessels might not contract from drying.-New York Journal of Medicine.

Modesty in conduct and judgment behoves every one-most of all, a young physician; it will procure him friends, and opportunities for instruction, and promote his eternal interests, as well as his internal improvement.-Hufeland. 